\title{
Simulation of coal low-temperature oxidation heating process in gob with “U+L" ventilation
}

\author{
Pei Ling ZHOU ${ }^{1,2}$, Ying Hua ZHANG ${ }^{1,2}$, Xu Jie SHEN ${ }^{1,2}$, Zhi An HUANG ${ }^{1,2, a}$, Yu Kun GAO ${ }^{1,2}$ \\ ${ }^{1}$ State Key Laboratory of High-Efficient Mining and Safety of Metal Mines(University of Science and Technology Beijing), Ministry of \\ Education, Beijing 100083, China \\ ${ }^{2}$ Mine Emergency Technology Research Center(University of Science and Technology Beijing), State Administration of production safety \\ supervision and administration, Beijing 100083, China
}

\begin{abstract}
In a gob with $\mathrm{U}+\mathrm{L}$ ventilation, a tail roadway exists, which has important effects on the oxidation heating process and gas concentration in gob areas. Research on the heating process and gas concentration in the " $\mathrm{U}+\mathrm{L}$ " ventilation can provide the basis for the prevention of spontaneous combustion, thus, the regularities of the oxidation heating process and gas concentration in gob areas were researched by simulation. Results showed that compared with $\mathrm{U}$ ventilation, $\mathrm{U}+\mathrm{L}$ ventilation caused the high temperature zone and high temperature points in the gob areas to increase in depth and width and to be influenced by the distance between the crossheading of the tail roadway and workface. The heating rate of the high-temperature point in the gob with tail roadway was 1.5 times of that in gob without tail roadway, but was unaffected by the location of the tail roadway. Tail roadway had diversion effects on the airflow, especially near return side and the maximum reduction of gas concentration can be $0.36 \%$.
\end{abstract}

\section{INTRODUCTION}

Spontaneous combustion in a gob is one of the major sources of coal mine disasters. Under a $U+\mathrm{L}$ ventilation condition, the effect of tail roadway on spontaneous combustion cannot be ignored. In research regarding spontaneous combustion "three-zone," many domestic and foreign scholars have focused on the gob areas of U-type ventilation; they have used theoretical analysis, experimental research, and numerical simulation to conduct research on the distribution of "three zones" in an air-flowing field and an oxygen concentration field, which reflects an actual situation [1-3] at a certain extent. However, research on the spontaneous combustion in the temperature field is limited.

On the other hand, Su Quan-zhi [4] conducted research on the spontaneous combustion in the pressure field and air-flowing field in a gob with $U+L$ ventilation $[5,6]$. The result showed that the existence of tail roadway made the pressure field change in a gob, thus leading to the offset of spontaneous combustion zones to tail roadways in the air-flowing field and increasing the risk of spontaneous combustion. Hence, the effect of tail roadways on spontaneous combustion in a gob cannot be

\footnotetext{
${ }^{a}$ Corresponding author:huang_za@qq.com
} 
ignored. However, studying a pressure field or an air-flowing field alone cannot fundamentally reflect the spontaneous combustion characteristics in a gob. As an indicator of spontaneous combustion, temperature is a significant parameter to be studied. Therefore, from the perspective of multi-field coupling, conducting research on the spontaneous combustion "three-zone" in a gob with tail roadway and combining the pressure field, air-flow field, and temperature field will yield results that are close to the actual situation and have important implications for production.

\section{MODELING OF MULTI-FIELD COUPLING}

\subsection{Mathematical model of multi-field coupling}

A gob area is a porous medium system consisting of caving rock mass and residual coal. Spontaneous combustion is a result of the interaction and mutual coupling of internal pressure, air flow, oxygen concentration, and temperature. Spontaneous combustion is a result of the interaction and mutual coupling of internal pressure, air flow, oxygen concentration, and temperature [7-10]. In a gob with $\mathrm{U}+\mathrm{L}$ ventilation, a mathematical model of multi-field coupling can be established by using the simultaneous governing equations of temperature field, pressure field, and oxygen concentration field. We can obtain a 3D mathematical model of the low-temperature oxidation of coal by using the following equation:

$$
\left\{\begin{array}{c}
\frac{\partial \bar{Q}_{x}}{\partial x}+\frac{\partial \bar{Q}_{y}}{\partial y}+\frac{\partial \bar{Q}_{z}}{\partial z}=0 \\
\frac{\partial C}{\partial \tau}+\bar{Q}_{x} \cdot \frac{\partial C}{\partial x}+\bar{Q}_{y} \cdot \frac{\partial C}{\partial y}+\bar{Q}_{z} \cdot \frac{\partial C}{\partial z}=D_{e}\left(\frac{\partial^{2} C}{\partial x^{2}}+\frac{\partial^{2} C}{\partial y^{2}}+\frac{\partial^{2} C}{\partial z^{2}}\right)-V(T) \\
\rho_{e} c_{e} \frac{\partial T}{\partial \tau}=q(T)+\lambda_{e}\left(\frac{\partial^{2} T}{\partial x^{2}}+\frac{\partial^{2} T}{\partial y^{2}}+\frac{\partial^{2} T}{\partial z^{2}}\right)-\rho_{g} c_{g}\left(\bar{Q}_{x} \cdot \frac{\partial T}{\partial x}+\bar{Q}_{y} \cdot \frac{\partial T}{\partial y}+\bar{Q}_{z} \cdot \frac{\partial T}{\partial z}\right) \\
\frac{\partial}{\partial x}\left(K_{x} \frac{\partial H}{\partial x}\right)+\frac{\partial}{\partial y}\left(K_{y} \frac{\partial H}{\partial y}\right)+\frac{\partial}{\partial z}\left(K_{z} \frac{\partial H}{\partial z}\right)=0
\end{array}\right.
$$

In multivariate equations, $\mathrm{x}, \mathrm{y}$, and $\mathrm{z}$ are the coordinates of $3 \mathrm{D}$ space; $\bar{Q}$ is the leakage flow rate; $\mathrm{K}$ is the absolute permeability; $\mathrm{C}$ is the concentration of $\mathrm{O} 2$ (the value is $24 \%$ ); $\mathrm{D}$ is the oxygen diffusion coefficient in coal; $\mathrm{V}(\mathrm{T})$ is the actual oxygen uptake rate; $\mathrm{H}$ is the partial pressure of heat. These equations are convection diffusion governing equations, chemical reaction governing equations, heat transfer governing equations, and momentum transfer governing equations.
A calculation model was established with a tail roadway. On the basis of the coal-oxygen reaction mechanism, a UDF computation program was written and imported to FLUENT.

\subsection{Modeling gob of $U+L$ ventilation}

A certain mine was utilized as a prototype, and a geometric model of a gob was built. The gob trend was researched in $100 \mathrm{~m}$. The working surface length was 100 $\mathrm{m}$; the height was $10 \mathrm{~m}$; the ventilation airways were 4.4 $\mathrm{m}$ wide, $2.6 \mathrm{~m}$ high, and $10 \mathrm{~m}$ long; the tail roadway was $3.5 \mathrm{~m}$ wide, $2.2 \mathrm{~m}$ high, and $5 \mathrm{~m}$ long.

From the working surface to the distance, the caving zone in gob was divided into three zones: the natural accumulation area $(10 \mathrm{~m})$, load influence zone $(30 \mathrm{~m})$, and compaction stability region $(60 \mathrm{~m})$; these zones were named a, b, and c, respectively. Accoding to the working surface data and calculating formula, the bulking coefficients are $\mathrm{K}_{\mathrm{pa}}=1.94, \mathrm{~K}_{\mathrm{pb}}=1.87$, and $\mathrm{K}_{\mathrm{pc}}=1.5$. The relationship between porosity and bulking coefficient is $\varepsilon=1-\frac{1}{K}$; thus, the porosity of each district is $0.61,0.58$, and 0.46; $\mathrm{D}_{\mathrm{ma}}=0.35,1 / \alpha_{\mathrm{a}}=2850$, and $\mathrm{C}_{\mathrm{a}}=45.1 ; \mathrm{D}_{\mathrm{mb}}=$ $0.2,1 / \alpha_{b}=10700$, and $\mathrm{C}_{\mathrm{b}}=93.1 ; \mathrm{D}_{\mathrm{mc}}=0.1,1 / \alpha_{\mathrm{c}}=$ 181000 , and $C_{c}=632, D_{m}$ is the average particle diameter, $1 / \alpha$ is the viscous drag coefficient, and $\mathrm{C}$ is the inertial resistance coefficient.

\section{MODEL VERIFICATION}

Owing to the limitations in production and cost, field verification cannot be conducted. The simulation experiments were conducted in a laboratory to validate the model. Given that the temperature distribution in a gob is the simulation result of multi-field states and physical parameters, the multi-field states, physical parameters, model will be correct if the temperature rising law is correct. In this case, the simulation results after changing the simulation materials are also correct. Considering that the oxidation heating rate of coal is slow, spontaneous combustion phenomena will occur only in accumulation and good thermal conditions. Accordingly, we selected pyrite as material, which had a fast oxidation heating rate.

On the basis of the similarity criteria for dimensional analysis, combining the actual situation at the scene, and 
according to a similarity ratio of 1:200, the model was designed with stainless steel housing and within 30 mm-thick extruded polystyrene board insulation materials. The content was $520 \mathrm{~mm} \times 500 \mathrm{~mm} \times 50 \mathrm{~mm}$, and the size of both intake and return gates was $50 \mathrm{~mm} \times 50 \mathrm{~mm}$ $\times 50 \mathrm{~mm}$.

The model verification was conducted as follows. First, a numerical simulation was performed. The model and multi-field parameters above were used. The volume was as large as the volume of the similar model. The material was pyrite. Second, a similar simulation experiment was conducted, and the temperature distribution of pyrite was simulated. The physical map of the model and the temperature monitoring points are shown in Figure 1. Third, the simulation results were validated with the test data. If the simulation results were in good agreement when the simulation material was pyrite; thus, the model was correct. In this case, the simulation would also be correct when the simulation material was coal. Thus, the correctness of the simulation model could be verified.
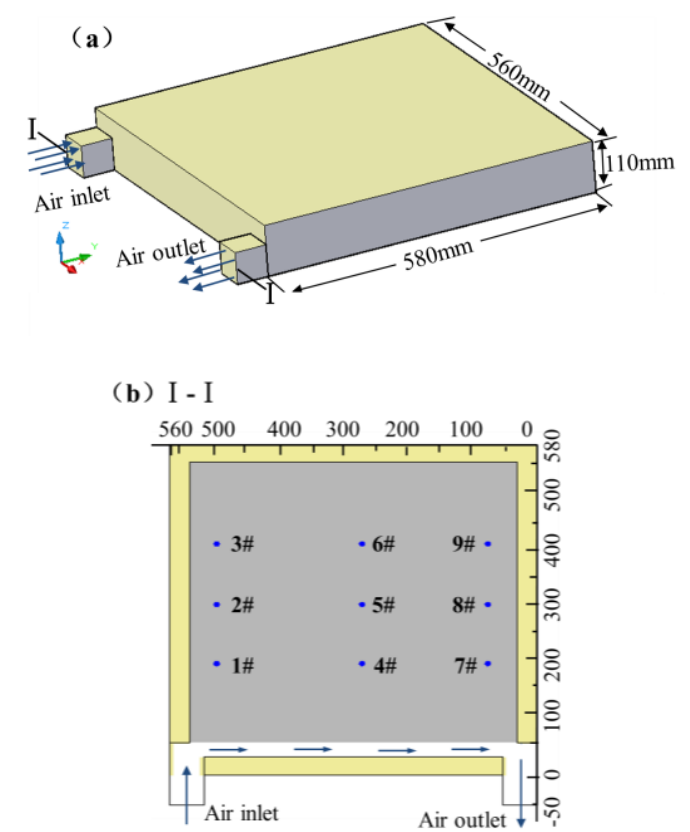

Figure 1. Model map and measurement point position

In Fig. 1, the \#1, \#2, and \#3 thermocouples were in the inlet side, whereas the $\# 7, \# 8$, and \#9 thermocouples were in the outlet side. The validation was divided into two steps. Temperature distribution of the reaction after $10 \mathrm{~h}$ was verified. The comparison results are shown in Figure 2. From Figure 2, the results of similar experiments were consistent with the results of numerical simulation; thus, the correctness of the model was verified.

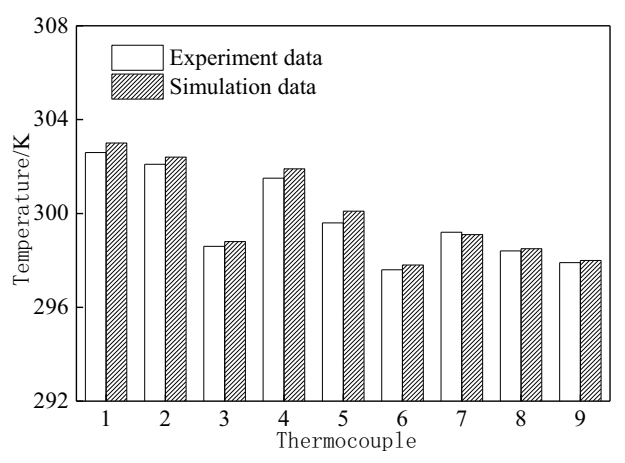

Figure 2. Temperature after 9 hours of simulation and experiment

\section{RESULTS AND ANALYSIS}

\subsection{Low-temperature oxidation heating process in gob with " $U+L$ " ventilation}

The temperature field was gained because of the heat storing in gob areas caused by the oxidation reactions between coal and oxygen. The oxidation heating process of temperature filed in gob was shown in Figure 3. The temperature field and changes on day 1, 4, 7 and 10 were shown in (a), (b), (c) (d). The average temperature in gob areas increased as the oxidation of coal proceeded, and the high-temperature areas basically occurred on day 4 with a depth of $60 \mathrm{~cm}$.

Owing to the outflow of air in tail roadway, the width of the spontaneous combustion zone in the return side was small, the spontaneous combustion zone became wide and deep in the oxygen concentration field, the frequency factor of deep coal for reaction was increased. Consequently, the heat release of reaction increased, the temperature increased, and the high-temperature belt became wide and deep.

Given that the tail roadway lied in the porous media, heat flowed out from it; thus, the temperature increased significantly near the tail roadway. In the return side areas, the temperature was highest near the tail roadway, approximately $3.3 \mathrm{~K}$ higher than the ambient temperature.

The temperature curve of high temperature point changing with time was shown in Figure 4. The temperature of high temperature point increased exponentially. The temperature was increased to $312.8 \mathrm{~K}$ from the initial value on day 10 with a increasing heating 
rate and the increased risk of spontaneous combustion.

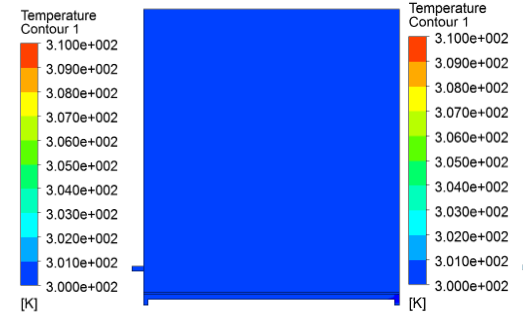

(a)

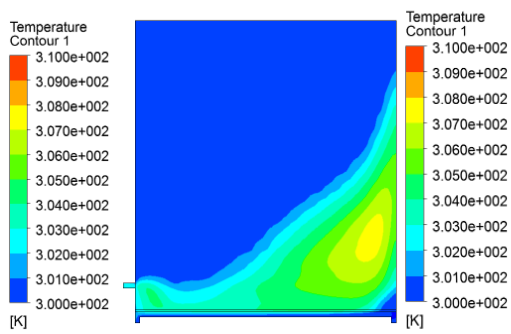

(c)

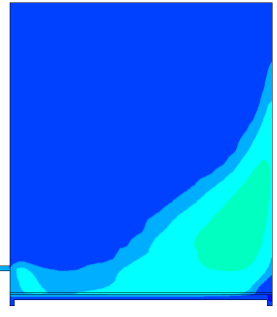

(b)

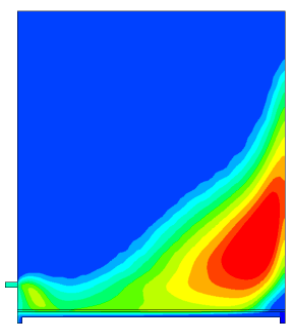

(d)
Figure 3. Oxidation heating process of temperature filed in gob. (a) 1d;(b)4d; (c)7d; (d) 10d

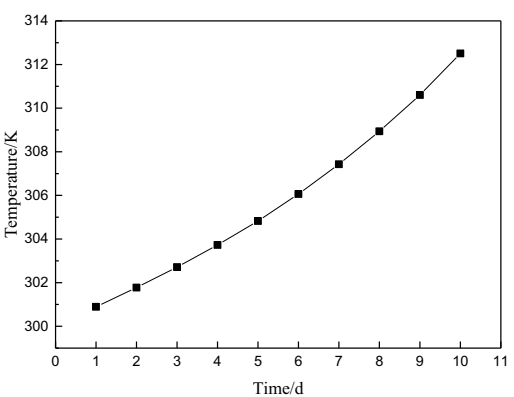

Figure 4. Temperature of high temperature point changing with time

The preceding results indicated that the existence of tail roadway affected oxidation heating process, thus, temperature in gob was affected. The location of the tail roadway also affected the oxidation heating process and temperature field.

\subsection{Influence of the position of tail roadway on the temperature field in gob areas}

The distribution law of the temperature field within 10 days was calculated to analyze the influence of tail roadway on the temperature field in gob mainly from the two aspects of the high-temperature point. The depth and temperature of high temperature point was shown as Figure 5.
(1) Comparison of the $U$ and $U+L$ ventilations indicated that the tail roadway had a great influence on the location and the temperature of the high-temperature points. The heating rate of the high-temperature point was $0.8(\mathrm{~K} / \mathrm{d})$ when no tail roadway existed, but it can be 1.24 $(\mathrm{K} / \mathrm{d})$ when tail roadway existed, heating rate of the high-temperature point in the gob of $\mathrm{U}+\mathrm{L}$ ventilation was 1.5 times of that in $U$ ventilation.

(2) The location of tail roadway had an no influence on the high-temperature point. neither the depth and temperature of high temperature point none changed with the different distance. When the distances between the crossheading and working surface were 5, 10, 15, 20, and $30 \mathrm{~m}$, the heating rates were $1.09,1.11,1.13,1.15$, and $1.24(\mathrm{~K} / \mathrm{d})$, respectively.

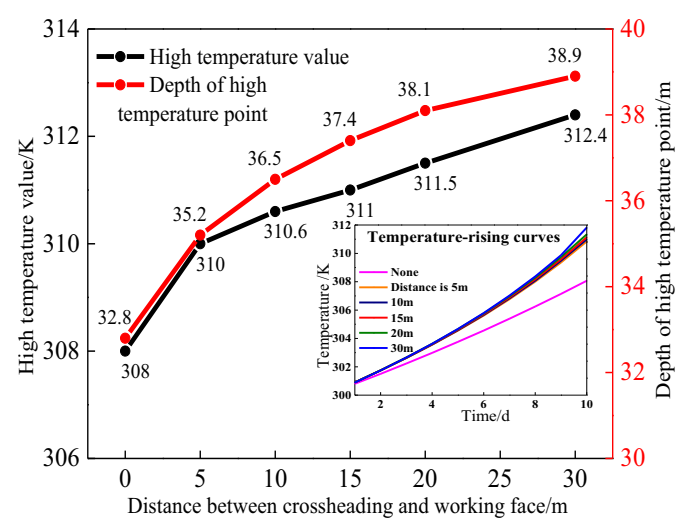

Figure 5. Effects of the distance between crossheading and workface on the high temperature points in gob

\subsection{Flowrate of tail roadway and the distribution of gas concentration}

The use of tail roadway had an effect on oxidation heating process in gob areas while the tail roadway was mainly used for gas drainage. The Figure 6 show that flowrate of roadway when differential pressure of tail roadway and outlet was different, while the distance between crossheading and workface was $20 \mathrm{~m}$, differential pressure of inlet and outlet was 200pa, and differential pressure of outlet and tail roadway was $0 \mathrm{~Pa}, 20 \mathrm{~Pa}, 50 \mathrm{~Pa}, 100 \mathrm{~Pa}$, $200 \mathrm{~Pa}$.

With the increasing of differential pressure of outlet and tail roadway, flowrate of outlet decreasing, but flowrate of tail roadway increasing. The flowrate of tail roadway became greater than outlet when the differential 
pressure was more than $150 \mathrm{pa}$, this is the results of that a large part of the airflow flows out from the tail roadway.

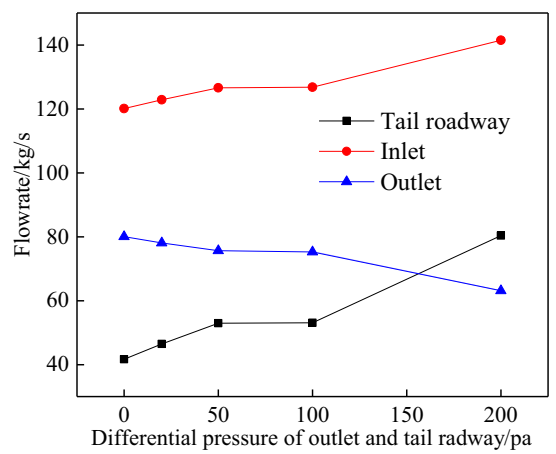

Figure 6. Flowrate of roadway when differential pressure of tail roadway and outlet was different

In the gob with " $U+L$ " ventilation, due to the diversion effects of the tail roadway on the airflow, the gas concentration was affected too. It can be seen from Figure 7 that the maximum reduction of gas concentration was about $0.36 \%$ in the position $10 \mathrm{~m}$ away from return side, and the maximum reduction of gas concentration was about $0.32 \%$ in the position $100 \mathrm{~m}$ away from return side. The gas concentration $50 \mathrm{~m}$ from workface shown in (a) and (b) of Figure 7 in areas $10 \mathrm{~m}$ and $100 \mathrm{~m}$ from return side decreased by $0.09 \%$ and $0.02 \%$. The gas concentration $250 \mathrm{~m}$ from workface in areas $10 \mathrm{~m}$ and $100 \mathrm{~m}$ from return side decreased by $0.36 \%$ and $0.32 \%$. In the areas nearer from the outlet, the differences of gas concentration in gob between with and without tail roadway were larger and it could be concluded that the gas drainage was best in the gob with $\mathrm{U}$ and $\mathrm{L}$ ventilation.

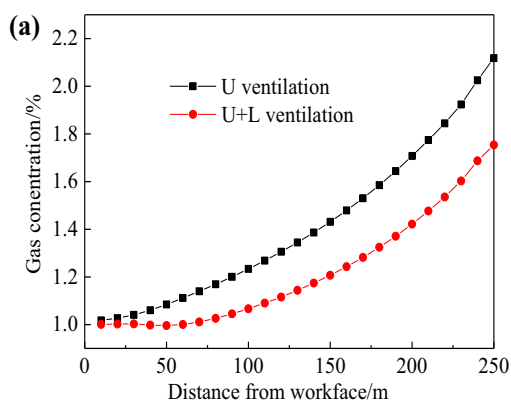

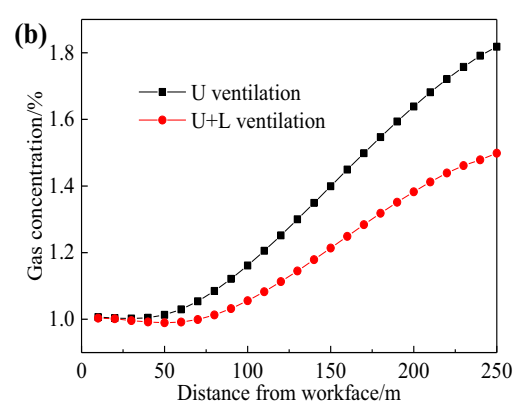

Figure 7. Gas concentration contrast in gob with " $U$ " and " $U+L$ " ventilation. (a) $10 \mathrm{~m}$ from return side; (b) $100 \mathrm{~m}$ from return side

\section{CONCLUSION}

(1) The existence of tail roadway had a great influence on the heating process, the temperature near the tail roadway, approximately $3.3 \mathrm{~K}$ higher than the ambient temperature in the return side areas.

(2) Compared the gob with $U$ and $U+L$ ventilation systems, in the gob with a $\mathrm{U}+\mathrm{L}$ ventilation, the location of high-temperature points was deeper and the temperature was higher, heating rate of the high-temperature point in the gob of $\mathrm{U}+\mathrm{L}$ ventilation was 1.5 times of that in $\mathrm{U}$ ventilation .

(3) The distance between the crossheading of tail roadway and working surface had no effects on high temperature in the gob.

(4) Tail roadway had diversion effects on the airflow, and the gas drainage effect was the best near return side, the maximum reduction of gas concentration can be $0.36 \%$

\section{References}

[1] J. Huang, S. Q. Yang, X. T. Chu, Q. Xu. Numerical Simulation on Air leakage flow field in spontaneous combustion three zone of goaf. Coal Sci. Techol. 37(2009)

[2] L. M. Yuan, C. A. Smith, Numerical study on effects of coal properties on spontaneous heating in longwall gob areas. Fuel. 87(2008)

[3] K. Brooks, D. A. Glasser. simplified model of spontaneous combustion in coal stockpiles. Fuel. 65(1986)

[4] Q. Z. Su. Study on variation law of spontaneous combustion "three-zone "in gob areas of fully mechanized coal face. PhD thesis, Taiyuan University of Technology, 
Taiyuan, China.

[5] K. Wang, S. G. Jiang, W. Q. Zhang, Z. Y. Wu. Numerical simulation of tail roadway change to gas flow field in goaf. J. Min. Saf. Eng. 29(2012)

[6] S. Q. Yang, T. Cheng, Q. Xu, W. L. Lv, J. Huang. Theoretical analysis and numerical simulation of influence of the change of negative pressure and air volume of inner interlocked tail road on coal spontaneous combustion. J. Chin. Coal Soc. 36(2011)

[7] W. Liu. (2014) Multi-physics coupling mechanism and three-dimensional numerical simulation of spontaneous combustion of gob areas. PhD thesis, Chin. Univ. Min. Techno. Beijing, China.

[8] Q. L. He, D. M. Wang. Numerical simulation of spontaneous combustion process in goaf areas by fully-mechanized caving roof coal. J. Chin. Univ. Min. Technol. 33(2004)

[9] H. Y. Niu, X. H. Zhang. Research on the coal self - ignition and prevention techniques classification. Industrial Saf. Environ. protection. 33(2007)

[10] M. G. Yu, X. H. Chang, H. L. Jia. L. X. Lu. analysis of spontaneous combustion three zone in goaf based on Matlab. J. Chin. Coal Soc. 35(2010) 